\title{
Chronic Periodontitis and C-Reactive Protein Levels
}

Isaac Suzart Gomes-Filho, * Julita Maria Freitas Coelho, ${ }^{\dagger}$ Simone Seixas da Cruz, ${ }^{\ddagger}$ Johelle Santana Passos, ${ }^{*}$ Camila Oliveira Teixeira de Freitas, ${ }^{*}$ Naiara Silva Aragão Farias, * Ruany Amorim da Silva,§ Milena Novais Silva Pereira," Thiago Lopes Lima, and Maurício Lima Barreto

Background: This study aims to analyze the relationship between chronic periodontitis and C-reactive protein (CRP) by considering associated variables in individuals with or without cardiovascular disease.

Methods: A sample of 359 individuals of both sexes (aged $\geq 40$ years) was assessed. Among these individuals, 144 subjects were admitted to the hospital because of a first occurrence of acute myocardial infarction; 80 subjects were in the hospital for reasons other than acute myocardial infarction; and 135 subjects were living in the community. A questionnaire was applied to obtain demographic and lifestyle characteristics. Complete clinical periodontal examinations and anthropometric assessments were performed. CRP levels, plasma glucose levels, lipid profiles, and blood tests were performed to investigate any conditions that might have suggested infection and/or inflammation. CRP evaluations were performed using nephelometry. Individuals were considered to have periodontal disease if they simultaneously presented at least four teeth with one or more sites with probing depth $\geq 4 \mathrm{~mm}$, clinical attachment loss $\geq 3 \mathrm{~mm}$, and bleeding on probing. Procedures for descriptive analyses and logistic regression were used.

Results: In the chronic periodontitis group, mean CRP levels were higher than those in the group without chronic periodontitis $(2.6 \pm 2.6 \mathrm{mg} / \mathrm{L}$ versus $1.78 \pm 2.7 \mathrm{mg} / \mathrm{L}$, respectively). The final model showed that individuals with chronic periodontitis were more likely to have high CRP levels (adjusted odds ratio: 2.26; $95 \%$ confidence interval: 1.30 to 3.93 ) considering the effects of age, schooling level, sex, smoking, high-density lipoprotein cholesterol, and diabetes.

Conclusion: In this study, chronic periodontitis is associated with elevated plasma CRP levels, even after controlling for several potential confounders. J Periodontol 2011;82: 969-978.

\section{KEY WORDS}

C-reactive protein; inflammation; myocardial infarction; periodontitis.

\footnotetext{
* Department of Health, Feira de Santana State University, Feira de Santana, BA, Brazil. $\dagger$ Department of Biological Sciences, Feira de Santana State University.

\$ Section of Epidemiology, Federal University of Vale do São Francisco, Vale do São Francisco, PE, Brazil.

$\S$ School of Dentistry, Federal University of Bahia, Salvador, BA, Brazil.

II Bahia Foundation for the Development of Science, Salvador, BA, Brazil.

If Public Health Institute, Federal University of Bahia.
}

A ssociations between periodontitis and systemic diseases such as cardiovascular events have been much discussed within the scientific community..$^{1,2}$ One possible mechanism for such associations would involve the elevation of inflammatory markers like C-reactive protein (CRP). CRP is an extremely sensitive and non-specific acute-phase marker for inflammation that is produced in response to many forms of injury other than periodontitis, such as other infections, trauma, and hypoxia, ${ }^{3}$ and it is regulated by cytokines (interleukin [IL]- 6 and -1 and tumor necrosis factor-alpha [TNF- $\alpha$ ]). Its concentration changes over time in healthy individuals and increases with age, presumably as a reflection of increasing incidence of subclinical pathologic conditions. CRP presents associations with smoking, obesity, coffee consumption, triglycerides, diabetes, and periodontal disease. ${ }^{4,5}$

Normal CRP levels vary among populations, with mean values between 2.5 and $5.0 \mathrm{mg} / \mathrm{L} .{ }^{6}$ However, through the use of ultrasensitive methods, it is possible to detect CRP levels $\geq 0.9 \mathrm{mg} / \mathrm{L}$. One method for achieving this is hypersensitive immunonephelometry (also known as high-sensitivity or ultrasensitive immunonephelometry), which currently seems to be the method of choice for determining serum CRP concentrations, as seen in many published studies. ${ }^{7-10}$

doi: 10.1902/jop.2010.100511 
Strong evidence exists that suggests that CRP can be used as an important risk marker for future coronary disorders, ${ }^{11,12}$ which has increased the interest in studying CRP. According to the Centers for Disease Control and Prevention/American Heart Association, CRP levels $>3 \mathrm{mg} / \mathrm{L}$ indicate a high risk of cardiovascular diseases (CVDs), whereas CRP levels of 1 to 3 $\mathrm{mg} / \mathrm{L}$ suggest a medium risk, and CRP levels $<1 \mathrm{mg} / \mathrm{L}$ suggest a low risk. ${ }^{13,14}$ It was demonstrated that even slight increases in CRP were enough to be considered cardiovascular risk factors, independent of other risk factors that are already known. CRP also has a capacity to prognose acute coronary syndromes, with an ability to predict future cardiovascular events among apparently healthy individuals. ${ }^{15-17}$

A number of studies demonstrated an association between periodontal disease and the risk of CVDs. ${ }^{18,19}$ Nonetheless, this relationship has not yet indicated a causal association. Recent studies demonstrated that periodontitis contributed to increasing serum CRP levels, ${ }^{20-25}$ and it is conceivable that elevated CRP levels in periodontitis can, at least in part, explain the association between periodontal disease and CVD. However, this association was not identified by Bretz et al., ${ }^{26}$ and reductions in CRP levels were not always observed after periodontal therapy. ${ }^{27,28}$

In this regard, the present study aims to estimate the association between chronic periodontitis and serum CRP levels in individuals with or without cardiovascular disease.

\section{MATERIALS AND METHODS}

This study consisted of a cross-section from a casecontrol study that was conducted among individuals $\geq 40$ years of age with the initial purpose of investigating the association between periodontal disease and acute myocardial infarction (AMI) among cases of an initial AMI event and hospital and community controls. The participants were selected in Salvador, BA, Brazil, between September 2008 and April 2009. To make up the sample for the previous study, the individuals included needed to have a minimum of four teeth, not be pregnant, not present any diagnosis of neoplasia or human immunodeficiency virus/acquired immunodeficiency syndrome, not have made use of an anti-inflammatory medication over the preceding 2 months, and not have undergone any previous periodontal treatment over the preceding 6 months. The exclusion criteria were related to individuals with previous infarction events, histories of percutaneous coronary revascularization within the preceding 6 months or surgical revascularization over the preceding 2 months, and hospital stays $>7$ days.

All participants in the previous study who were $\geq 40$ years of age and for whom CRP assays were available were included in this cross-sectional study and, thus, produced a sample of 359 individuals. Among these, 144 subjects had been admitted to the hospital because of a first occurrence of AMI; 80 subjects were in the hospital for reasons other than AMI; and 135 subjects were living in the community. The study protocol was approved by the Research Ethics Committee of Feira de Santana State University (protocol 025/2004), and all participants signed a free and informed consent statement.

\section{Interview and Clinical Periodontal Examination}

First, participants answered a questionnaire at an interview. The questionnaire sought information relating to identification, sociodemographic data, general health characteristics, oral health characteristics, and lifestyle habits.

After this, all participants underwent a clinical periodontal examination conducted by a previously trained dentist (JMFC). For hospitalized individuals, oral examinations were made $\leq 7$ days after admission.

To diagnose cases of chronic periodontitis, the following measurements were obtained: probing depth (PD), gingival recession (GR), clinical attachment loss (AL), bleeding on probing (BOP), visible plaque index (VPI), ${ }^{29}$ and number of teeth present in the mouth. The PD, which was defined as the distance from the gingival margin to the most apical extent of probe penetration, was ascertained at six sites per tooth ${ }^{30}$ for all teeth present in the mouth (with the exception of third molars). At each of these sites, $\mathrm{BOP}^{29}$ and gingival recession measurements were obtained, and the clinical AL was calculated. The recession measurement consisted of the distance from the gingival margin to the cemento-enamel junction, whereas the clinical AL consisted of the result from summing the PD and GR. ${ }^{31}$ As a descriptor for the periodontal condition, the VPI was also evaluated on the four faces of each tooth (vestibular, lingual, mesial, and distal). ${ }^{29}$ All measurements were made using a Williams probe marked out in millimeters."

Individuals were considered to have a diagnosis of chronic periodontitis if they presented $\geq 4$ teeth on which $\geq 1$ site showed PDs $\geq 4 \mathrm{~mm}$, clinical $\mathrm{AL} \geq 3$ $\mathrm{mm}$, and BOP at the same site. ${ }^{32}$

All examinations were performed by a single dentist (JMFC) who received prior training from a specialist in periodontics (ISGF). At the start of the data gathering, the measurements on $10 \%$ of the sample were repeated by the examiner to obtain the withinexaminer evaluation. The reproducibility and concordance of clinical measurements were calculated by means of the within-examiner $\kappa$ index. The value

\# Hu-Friedy, Chicago, IL. 
obtained for probing depths was 0.87 , which was considered to be a strongly positive association, thereby proving the efficacy of the calibration.

\section{Laboratory Tests}

Blood samples for laboratory tests on CRP were obtained by means of venous puncture and analyzed at the laboratory of two hospitals (Santa Izabel Hospital and Ana Nery Hospital, Salvador, Bahia, Brazil), after 12 hours of fasting and under standardized conditions. The technique of immunonephelometry with anti-CRP monoclonal antibodies was used in this study, which allowed quantitative results (in milligrams per liter) to be obtained. CRP levels were analyzed as indicated by the Centers for Disease Control and Prevention/American Heart Association. ${ }^{13,14}$

From the same sample of peripheral blood that was collected for the CRP evaluation, blood glucose, triglyceride, total cholesterol, high-density lipoprotein cholesterol (HDL-C), and low-density lipoprotein cholesterol (LDL-c) levels were tested, a complete hemogram was run, and creatinine and urea assays were performed.

\section{Other Complementary Assessments}

Body mass index (BMI) values were obtained from weight and height measurements of subjects, and these were interpreted as recommended by the Brazilian Association for Obesity and Metabolic Syndrome Studies. ${ }^{33}$ The criteria were adapted to facilitate interpretation of the data by means of the aggregation of categories into two levels: normal weight, corresponding to $B M I \leq 25 \mathrm{~kg} / \mathrm{m}^{2}$, and overweight or obese, corresponding to $B M I>25 \mathrm{~kg} / \mathrm{m}^{2}$. The waist/hip ratio (WHR) was obtained by dividing the waist-circumference measurement by the hip-circumference measurement. These measurements of study participants were obtained using an inelastic measuring tape. Men with a WHR of 0.90 to 0.99 and women with a WHR of 0.80 to 0.84 were classified as overweight, whereas men with a WHR $\geq 1.00$ and women with a WHR $\geq 0.85$ were classified as obese. ${ }^{34}$

\section{Study Variables}

The main independent variable was chronic periodontitis, and this was categorized as absent or present. The dependent variable (i.e., CRP) was used on a continuous scale and dichotomized as $<3 \mathrm{mg} / \mathrm{L}$ (low and medium risk) and $\geq 3 \mathrm{mg} / \mathrm{L}$ (high risk), with the aim of evaluating high-risk cases. The following covariables were taken into consideration in the analyses: age, sex, self-declared race/color, schooling level, per capita income, religion, marital situation, physical activity practice, smoking habit currently or in the past, alcohol consumption, BMI, normal blood glucose level, normal total cholesterol, normal LDL-c, normal HDL-c, normal WHR, and the presence of systemic arterial hypertension. Categorization of continuous variables, when required, was done based on their distribution or in accordance with cutoffs identified in the literature.

\section{Data Analyses}

First, both the $\chi^{2}$ and Student $t$ tests (or the MannWhitney $U$ test) were used to investigate the distribution of covariables between groups with and without chronic periodontitis $(P \leq 0.05)$. In evaluating the association between chronic periodontitis and CRP, odds ratios (ORs) and their respective 95\% confidence intervals (CIs) were calculated as association measurements. In a stratified analysis, covariables that were possible effect modifiers were investigated by means of the Mantel-Haenszel test using a significance level of $P \leq 0.20$. Potential confounding variables were selected on theoretical and empirical bases taking into consideration relative differences $>20 \%$ between measurements of each covariable adjusted using the Mantel-Haenszel method and the crude-association measurements. In an unconditional logistic regression analysis, the presence of effect-modifying covariables was investigated using the maximum-likelihood ratio test $(P<0.05)$ comparing models with and without the product terms. For variables that were not identified empirically as effect modifiers, the role of the confounding variable was evaluated by means of a backward strategy. Variables that produced changes $\geq 10 \%$ in the association measurement were taken to be potential confounding variables. On theoretical grounds, classic confounders were kept in the final model despite the empirical evidence from this study and were also kept in a model that was adjusted by considering a subsample in which individuals hospitalized for reasons other than AMI or angina were excluded.

\section{RESULTS}

The sample was formed by 359 individuals (181 males and 178 females; mean age: $59 \pm 11.1$ years). According to the periodontal diagnostic criteria used, 91 individuals were identified as presenting chronic periodontitis, whereas the remaining 268 were free from this disease.

Sociodemographic and lifestyle characteristics, in relation to the subjects' periodontal conditions are presented in Table 1. The data indicates that a larger proportion of the individuals with chronic periodontitis were $<59$ years of age compared to individuals without periodontitis, as well as in relation to a mixed/ black skin color, schooling level $>4$ years, a high WHR, the presence of smoking habit, consumption of alcoholic beverages, the absence of diabetes, and the presence of hypertension. However, the only significant difference was in relation to a past or 


\section{Table I.}

\section{Sociodemographic and Lifestyle Characteristics According to Periodontal Conditions of Study Participants ( $N=359$ )}

\begin{tabular}{|c|c|c|c|}
\hline Characteristic & With Periodontitis $(n=9 \mid)$ & Without Periodontitis $(n=268)$ & $p^{*}$ \\
\hline \multicolumn{4}{|l|}{ Age } \\
\hline$<59$ years $(\mathrm{n}[\%])$ & $52(57.1)$ & $134(50.0)$ & \multirow{5}{*}{0.24} \\
\hline$\geq 59$ years $(\mathrm{n}[\%])$ & $39(42.9)$ & $134(50.0)$ & \\
\hline Mean \pm SD (years) & $59.2 \pm 10.96$ & $58.7 \pm 11.14$ & \\
\hline Median (years) & 57.0 & 58.5 & \\
\hline Min. to max. (years) & 40 to 84 & 40 to 91 & \\
\hline \multicolumn{4}{|l|}{$\operatorname{Sex}(n[\%])$} \\
\hline Female & $44(48.3)$ & $134(50.0)$ & \multirow[b]{2}{*}{0.79} \\
\hline Male & $47(51.6)$ & $134(50.0)$ & \\
\hline \multicolumn{4}{|l|}{ Skin color (n [\%]) } \\
\hline White & $15(16.5)$ & $51(19.0)$ & \multirow[b]{2}{*}{0.59} \\
\hline Mixed/black & $76(83.5)$ & $217(81.0)$ & \\
\hline \multicolumn{4}{|l|}{ Per capita income $(\mathrm{n}[\%])^{\dagger}$} \\
\hline$>$ I minimum monthly salary & $35(38.5)$ & $104(38.8)$ & \multirow[b]{2}{*}{0.97} \\
\hline$\leq$ I minimum monthly salary & $56(61.5)$ & $164(61.2)$ & \\
\hline \multicolumn{4}{|l|}{ Religion (n [\%]) } \\
\hline Catholic & $58(63.7)$ & $173(64.6)$ & \multirow[b]{2}{*}{0.87} \\
\hline Other & $33(36.3)$ & $95(35.4)$ & \\
\hline \multicolumn{4}{|l|}{ Schooling (n [\%]) } \\
\hline$>4$ years of study & $54(59.3)$ & $139(51.9)$ & \multirow[b]{2}{*}{0.22} \\
\hline$\leq 4$ years of study & $37(40.7)$ & $129(48.1)$ & \\
\hline \multicolumn{4}{|l|}{ BMI } \\
\hline$<25 \mathrm{~kg} / \mathrm{m}^{2}$ (n [\%]) & $39(42.9)$ & $115(42.9)$ & \multirow{5}{*}{0.99} \\
\hline$\geq 25 \mathrm{~kg} / \mathrm{m}^{2}(\mathrm{n}[\%])$ & $52(57.1)$ & $153(57.1)$ & \\
\hline Mean $\pm \mathrm{SD}\left(\mathrm{kg} / \mathrm{m}^{2}\right)$ & $26.10 \pm 4.61$ & $26.53 \pm 5.21$ & \\
\hline Median $\left(\mathrm{kg} / \mathrm{m}^{2}\right)$ & 26.10 & 28.08 & \\
\hline Min. to max. $\left(\mathrm{kg} / \mathrm{m}^{2}\right)$ & I 5.82 to 37.52 & | 5.06 to 49.4 | & \\
\hline \multicolumn{4}{|l|}{ WHR } \\
\hline Normal (n [\%]) & $19(20.9)$ & $79(29.5)$ & \multirow{5}{*}{0.11} \\
\hline Increased (n [\%]) & $72(79.1)$ & $189(70.5)$ & \\
\hline Mean \pm SD & $0.98 \pm 0.17$ & $0.98 \pm 0.11$ & \\
\hline Median & 1.0 & 0.96 & \\
\hline Min. to max. & 0.76 to 1.43 & 0.70 to 1.27 & \\
\hline \multicolumn{4}{|l|}{ Smoking habit (n [\%]) } \\
\hline No & $71(78.0)$ & $236(88.1)$ & \multirow[b]{2}{*}{0.008} \\
\hline Yes & $20(22.0)$ & $32(11.9)$ & \\
\hline \multicolumn{4}{|l|}{ Alcohol consumption (n [\%]) } \\
\hline No & $46(50.6)$ & $148(55.2)$ & \multirow[b]{2}{*}{0.44} \\
\hline Yes & $45(49.4)$ & $120(44.8)$ & \\
\hline \multicolumn{4}{|l|}{ Physical activity (n [\%]) } \\
\hline Active & $35(38.5)$ & $97(36.2)$ & \\
\hline Sedentary & $56(61.5)$ & $171(63.8)$ & 0.70 \\
\hline
\end{tabular}


Table I. (continued)

\section{Sociodemographic and Lifestyle Characteristics According to Periodontal Conditions of Study Participants $(\mathrm{N}=359)$}

\begin{tabular}{lccc}
\hline Characteristic & With Periodontitis $(n=91)$ & Without Periodontitis $(n=268)$ & $p^{*}$ \\
\hline Diabetes $(n[\%])$ & $75(82.4)$ & $206(76.9)$ & 0.27 \\
No & $16(17.6)$ & $62(23.1)$ & \\
Yes & & & \\
Hypertension (n [\%]) & $31(34.1)$ & $112(41.6)$ & 0.21 \\
No & $60(65.9)$ & $156(58.4)$ & \\
Yes &
\end{tabular}

Min. to max. $=$ minimum to maximum.

* $P \leq 0.05$.

$\dagger$ Brazilian minimum monthly salary was equivalent to 283.00 US dollars.

present smoking habit $(P=0.008)$. It can be emphasized that the other covariables (sex, per capita income, religion, BMI, and physical activity) presented very homogeneous proportions between the groups with and without chronic periodontitis.

Comparing clinical-laboratory characteristics with periodontal conditions between groups with and without chronic periodontitis (Table 2), it was observed that the mean CRP level, PD, clinical AL, BOP, LDL-c, HDL-c, and urea were higher among individuals with periodontitis. The mean numbers of teeth in the mouth and leukogram values were lower in the periodontitis group. However, the differences were significant only for CRP level, PD, clinical AL, and BOP.

In the stratified analysis, only the variable of past or present smoking habit was a potential confounder, and there were no effect modifiers at the 5\% level.

The multivariate regression analysis also did not present any evidence for interactions, although there was evidence for confounding with regard to smoking. However, it was decided to keep age, sex, schooling level, HDL-c, BMI, and diabetes as covariables in the model, independent of the empirical results and in accordance with the theoretical suppositions that recognized these factors as classic confounders. From the final model (Table 3 ), it was observed that the chance of presenting high CRP levels (>3 mg/L) in the group with periodontitis was also approximately twice as high as in the group without periodontitis, thereby maintaining statistical significance. The analysis of hospitalized cases with AMI or unstable angina only compared to supposedly healthy individuals from the same community as the cases gave similar results.

\section{DISCUSSION}

From the main finding of this study, it was seen that a positive association existed between the presence of chronic periodontitis and high serum CRP levels because it is biologically plausible that inflammatory mediators, especially IL- 1 and -6 and TNF- $\alpha$ are released under conditions of periodontitis and present the capacity to stimulate hepatocytes to produce CRP. In this manner, it can be expected that, in the presence of chronic periodontitis, higher serum CRP levels would be found. ${ }^{35,36}$ These results corroborated previous findings from several other authors, ${ }^{20,23,24,37-41}$ although the controversy regarding the hypothesis of linkage between periodontitis and elevated CRP levels still remains. ${ }^{27,28}$

In this regard, for the findings from the present investigation to be fully interpreted, it is necessary to consider that the data from this study were from research with the purpose to investigate the association between periodontal disease and cardiovascular diseases. On the other hand, one special strength of this study was the complete periodontal examinations performed to obtain clinical descriptors of periodontal disease. ${ }^{32}$ From these examinations, it was possible to make careful diagnoses of chronic periodontitis among the participants because serum CRP levels were expected to be higher when the intensity of periodontitis was greater. ${ }^{42,43}$ Because $10 \%$ of the sites examined in the oral cavity presented a pocket/sulcus depth $\geq 4 \mathrm{~mm}$, which would have already been enough for a systemic repercussion, the sample used in this study seemed to have been sufficient for detecting increased CRP levels among patients with periodontal disease. $20,42,44$

However, this increase did not occur in all individuals with periodontitis. There may have been some form of genetic susceptibility toward inflammatory hyperactivity that predisposed individuals toward such elevations or associations with other factors such as smoking and diabetes. ${ }^{37,44}$ In this regard, the value of using samples that made it possible to include individuals with different degrees of susceptibility needs to 
Table 2.

\section{Clinical Laboratory Characteristics According to Periodontal Condition of Study Participants ( $\mathrm{N}=359$ )}

\begin{tabular}{|c|c|c|c|}
\hline Characteristics & With Periodontitis $(N=9 \mid)$ & Without Periodontitis $(N=268)$ & $p *$ \\
\hline $\begin{array}{l}\text { Probing depth }(\mathrm{mm} \text {; mean } \pm \mathrm{SD}) \\
\text { Median } \\
\text { Min. to max. }\end{array}$ & $\begin{array}{l}2.9 \pm 0.7 \\
2.8 \\
1.2 \text { to } 6.0\end{array}$ & $\begin{array}{c}2.5 \pm 0.5 \\
2.4 \\
\text { I.I to } 4.9\end{array}$ & $<0.001$ \\
\hline $\begin{array}{l}\text { Clinical AL (mm; mean } \pm \mathrm{SD}) \\
\text { Median } \\
\text { Min. to max. }\end{array}$ & $\begin{array}{c}4.3 \pm 1.4 \\
4.2 \\
1.3 \text { to } 8.2\end{array}$ & $\begin{array}{c}3.6 \pm 1.0 \\
3.6 \\
1.6 \text { to } 7.9\end{array}$ & $<0.00$ । \\
\hline $\begin{array}{l}\text { Teeth present }(n ; \text { mean } \pm \mathrm{SD}) \\
\text { Median } \\
\text { Min. to max. }\end{array}$ & $\begin{array}{l}15.7 \pm 8.1 \\
\mid 4 \\
4 \text { to } 32\end{array}$ & $\begin{array}{l}16.3 \pm 8.1 \\
15 \\
3 \text { to } 32\end{array}$ & 0.55 \\
\hline $\begin{array}{l}\text { Leukogram }(\mathrm{mg} / \mathrm{dL} \text {; mean } \pm \mathrm{SD}) \\
\text { Median } \\
\text { Min. to max. }\end{array}$ & $\begin{array}{c}12,396.9 \pm 14,794.2 \\
9,500 \\
1,108 \text { to } 97,600\end{array}$ & $\begin{array}{c}12,436.4 \pm 16,346.7 \\
8,800 \\
1,027 \text { to } \mid 13,000\end{array}$ & 0.98 \\
\hline $\begin{array}{l}\text { Blood glucose }(\mathrm{mg} / \mathrm{dL} \text {; mean } \pm \mathrm{SD}) \\
\text { Median } \\
\text { Min. to max. }\end{array}$ & $\begin{array}{c}\mid 17.4 \pm 50.1 \\
98 \\
65 \text { to } 300\end{array}$ & $\begin{array}{l}117.9 \pm 53.7 \\
100 \\
90 \text { to } 415\end{array}$ & 0.94 \\
\hline $\begin{array}{l}\text { HDL cholesterol (mg/dL; mean } \pm \mathrm{SD}) \\
\text { Median } \\
\text { Min. to max. }\end{array}$ & $\begin{array}{c}39.1 \pm 11.9 \\
37.5 \\
16 \text { to } 90\end{array}$ & $\begin{array}{c}38.2 \pm 11.6 \\
37.0 \\
10 \text { to } 96\end{array}$ & 0.51 \\
\hline $\begin{array}{l}\text { Urea }(\mathrm{mg} / \mathrm{dL} ; \text { mean } \pm \mathrm{SD}) \\
\text { Median } \\
\text { Min. to max. }\end{array}$ & $\begin{array}{c}36.4 \pm 16.0 \\
34.5 \\
10.2 \text { to } 93\end{array}$ & $\begin{array}{c}34.5 \pm 15.2 \\
35.0 \\
10.0 \text { to } 96\end{array}$ & 0.11 \\
\hline
\end{tabular}

Min. to max. $=$ minimum to maximum.

* $P \leq 0.05$.

be emphasized. By examining 359 individuals, there was a large likelihood that this study would achieve success within this perspective, with sample means closer to population means (greater power).

Furthermore, the participants in the present study were diagnosed with chronic periodontitis in accordance with the classification proposed by GomesFilho et al. ${ }^{32}$ This classification uses at least four teeth with changes to three clinical descriptors: PD, clinical
$\mathrm{AL}$, and BOP. Combining these descriptors ensures that there is less possibility that individuals with periodontitis will have false-positive diagnoses (which is an important issue in association studies), and it ensures that they are included in the category of moderate severity of periodontitis of a localized extent because the criterion for classification in this group is that participants should present clinical AL $\geq 3 \mathrm{~mm}$ affecting $\geq 4$ teeth. 
Table 3.

\section{Association Between Chronic Periodontitis and High Levels of CRP ( $>3 \mathrm{mg} / \mathrm{L}$ ) in Patients}

\begin{tabular}{lccc}
\hline Models & OR & $95 \% \mathrm{Cl}$ & $P^{*}$ \\
\hline Crude $(\mathrm{N}=359)^{\dagger}$ & 1.93 & 1.34 to 2.76 & $<0.00$ । \\
Adjusted $(\mathrm{N}=359)^{\dagger \dagger}$ & 2.29 & 1.32 to 3.98 & 0.004 \\
Crude $(\mathrm{n}=279)^{\S}$ & 2.13 & 1.21 to 3.77 & 0.009 \\
Adjusted $(\mathrm{n}=279)^{\ddagger \S}$ & 2.16 & 1.20 to 3.90 & $0.01 \mathrm{I}$ \\
\hline
\end{tabular}

* $P \leq 0.05$.

$\uparrow$ Analyses performed on all study participants $(\mathrm{N}=359)$.

‡ Adjusted for age, sex, schooling level, smoking level, HDL-c, BMI, and diabetes

$\S$ Analyses performed excluding individuals hospitalized for reasons other than AMI $(n=279)$.

From this perspective, CRP levels found in this investigation could have been higher if the sample had been classified at the highest severity level (clinical AL $\geq 5 \mathrm{~mm}$ ) with a generalized extent. The doseresponse gradient has a direct influence on the organic response.

Another strength of the present study was the use of a high-sensitivity nephelometry technique to evaluate CRP levels that was capable of detecting variations $\geq 0.2 \mathrm{mg} / \mathrm{L}$. A variety of techniques for evaluating CRP levels were used in previous studies, ${ }^{27,28,45}$ along with the enzyme-linked immunosorbent assay test, $20,21,39$ which may cause difficulties in making comparisons between them.

In the literature, it was suggested that CRP is a nonspecific inflammatory marker that is sensitive to the classic confounding factors for periodontal disease, such as BMI, smoking, dyslipidemia, and hypertension, thus making it necessary to consider these variables in the study design and adjust for them at the time of analysis. ${ }^{1,32}$ It was also observed, for example, that HDL influences CRP levels, which justifies the application of modeling, even though some studies in the literature have made this type of adjustment. ${ }^{38,42}$ In the present investigation, cholesterol levels, cholesterol fractions, and triglycerides were assayed, arterial hypertension was assessed, and the influences of total and central obesity were investigated.

Likewise, certain socioeconomic factors such as low educational levels were correlated with a lower life expectancy and living conditions, which may have contributed toward the elevation of plasma CRP levels under such conditions. Increasing age may have also contributed toward such changes through the greater accumulation of body fat, sedentary lifestyles, and the presence of disease of an inflammatory nature, which are sometimes subclinical. ${ }^{46}$ Thus, restricting the ages of subjects to $\geq 40$ years, as done in the present study, seemed to be pertinent and appropriate.

The possibility of manifestations or systemic conditions that might have masked the effect of periodontal disease on serum CRP levels among study participants was also investigated by means of a questionnaire on current medical histories, along with a leukocyte assay. Nonetheless, the possibility that an inflammatory and/or infectious state might not have shown clinically or might not have been detected on the hemogram cannot be totally dismissed.

It was noteworthy that CRP levels were generally high in the study group (>3 mg/L). This was reported to represent a higher cardiovascular risk for groups with chronic periodontitis and groups without it. However, because the group with chronic periodontitis showed CRP levels of $\approx 40 \%$ greater than the levels in the group without chronic periodontitis, it is possible that a greater activity of periodontitis may have been responsible for these differences, particularly among individuals with a profile of high degrees of inflammation. Thus, the continuous monitoring of periodontal tissues is necessary, and special attention should be given to the possibility that chronic periodontitis might contribute toward occurrences of cardiovascular diseases. ${ }^{29,42}$

It was observed that the differences relating to sex among the study sample did not present a sufficient effect to interfere with serum CRP levels. These levels were slightly higher among women, but the difference was not statistically significant. However, it was reported in the literature ${ }^{47}$ that there is a certain trend for CRP levels to be higher among women than among men.

With regard to age, very similar CRP concentrations were found in the two groups of the present study, although they were high. The values may have been high because the study only included individuals $\geq 40$ years of age. The other sociodemographic variables analyzed in this sample were of a homogeneous nature, which facilitated the analysis and interpretation of results. However, it was reported in the literature that a lower socioeconomic level is more associated with higher CRP levels. ${ }^{48}$ Thus, the high rates of chronic periodontitis that were detected $(>25 \%)$ may have been the factor of greatest influence on these higher CRP levels in the present study sample.

In addition, it was sought to evaluate the CRP levels in individuals presenting (or suspected of presenting) AMI within the first 24 hours of the first symptoms because CRP levels may range from 20 to 2,000 times greater than baseline levels between 24 and 48 hours 
after the stimulus. ${ }^{49}$ This was evaluated with the aim of reducing the possibility that AMI might have influenced serum CRP levels. Despite the diversity of study participants regarding their hospitalization status (i.e., admitted to a hospital unit because of AMI or for reasons other than ischemic cardiovascular disease or not hospitalized [i.e. living within the community]), CRP levels were always higher among individuals with chronic periodontitis. Regarding CRP levels among the individuals hospitalized because of AMI, these levels were assayed within 24 hours after the first symptoms. Regarding the influence of CRP levels on the participants hospitalized for other reasons $(n=80)$, the association studied remained positive and significant even after excluding these individuals $(n=279)$, with an association measurement very close to that of the full sample. This suggested that, although the reason for hospitalization may have contributed to greater increases in CRP levels, ${ }^{50}$ this event did not cause any significant changes to the effect-measurement results.

The present study seeks to expand the knowledge relating to the influence of chronic periodontitis on occurrences of AMI by means of analyses in a subgroup of individuals with this cardiovascular condition and taking into account the elevation of serum CRP levels. The findings indicate that there is a positive association between the presence of chronic periodontitis and a greater severity of AMI (with ST-segment elevation). These results are in agreement with other studies on this topic, although they are not presented because of the small size of this subsample of individuals with a primary event of AMI. Nonetheless, they indicate that there is a need for additional studies with sufficient statistical power that might provide a better clarification of the effect of chronic periodontitis on AMI through the elevation of CRP levels.

In summary, taking these results and study limitations into account, this study reinforces the theory that chronic periodontitis seems to be capable of increasing plasma CRP levels, which may give rise to an increased risk of other diseases, such as AMI.

\section{CONCLUSIONS}

From the data of the present study, along with other recent data, it was concluded that chronic periodontitis may add to the inflammatory burden of individuals and thus raise CRP levels, which may result in a higher risk of cardiovascular diseases. Furthermore, evaluations of this acute-phase protein may constitute an important tool for identifying changes to the periodontal and systemic health of individuals, especially among individuals who are at high risk of periodontitis and cardiovascular diseases.

\section{ACKNOWLEDGMENTS}

The authors acknowledge the Research Support Foundation of the State of Bahia, Salvador, Bahia, Brazil, the National Council for Scientific and Technological Development, Brasilia, Brazil, the Federal University of Bahia, and Feira de Santana State University for financial support for the research. The authors reported no conflicts of interest related to this study.

\section{REFERENCES}

1. Cullinan MP, Ford PJ, Seymour GJ. Periodontal disease and systemic health: Current status. Aust Dent $J$ 2009;54(Suppl. 1):S62-S69.

2. Dorn JM, Genco RJ, Grossi SG, et al. Periodontal disease and recurrent cardiovascular events in survivors of myocardial infarction (MI): The Western New York Acute MI Study. J Periodontol 2010;81: 502-511.

3. Glurich I, Grossi S, Albini B, et al. Systemic inflammation in cardiovascular and periodontal disease: Comparative study. Clin Diagn Lab Immunol 2002;9: 425-432.

4. Saito M, Ishimitsu T, Minami J, Ono H, Ohrui $M$, Matsuoka H. Relations of plasma high-sensitivity Creactive protein to traditional cardiovascular risk factors. Atherosclerosis 2003;167:73-79.

5. Tüter G, Kurtis B, Serdar M. Evaluation of gingival crevicular fluid and serum levels of high-sensitivity Creactive protein in chronic periodontitis patients with or without coronary artery disease. $J$ Periodontol 2007;78:2319-2324.

6. Correia CR, Burini CR. Acute-phase positive reactive plasmatic proteins (in Portuguese). J Bras Reumat 2000; 36:26-34

7. Thomson SP, Gibbons RJ, Smars PA, et al. Incremental value of the leukocyte differential and the rapid creatine kinase-MB isoenzyme for the early diagnosis of myocardial infarction. Ann Intern Med 1995;122: 335-341.

8. Biasucci LM, Colizzi C, Rizzello V, Vitrella G, Crea F, Liuzzo G. Role of inflammation in the pathogenesis of unstable coronary artery disease. Scand J Clin Lab Invest 1999;230:12-22.

9. Sinisalo J, Paronen J, Mattila KJ, et al. Relation of inflammation to vascular function in patients with coronary heart disease. Atherosclerosis 2000;149: 403-411.

10. Ridker PM. C-reactive protein and the prediction of cardiovascular events among those at intermediate risk: Moving an inflammatory hypothesis toward consensus. J Am Coll Cardiol 2007;49:2129-2138.

11. Emerging Risk Factors Collaboration, Kaptoge S, Di Angelantonio E, et al. C-reactive protein concentration and risk of coronary heart disease, stroke, and mortality: An individual participant meta-analysis. Lancet 2010;375:132-140.

12. Everett BM, Kurth T, Buring JE, Ridker PM. The relative strength of $\mathrm{C}$-reactive protein and lipid levels as determinants of ischemic stroke compared with coronary heart disease in women. J Am Coll Cardiol 2006;48:2235-2242.

13. American Heart Association. Inflammation, heart disease and stroke: The role of C-reactive protein. Available at: http://www.americanheart.org/presenter. 
jhtml?identifier=4648. Accessed September 25, 2010.

14. Pearson TA, Mensah GA, Alexander RW, et al. Markers of inflammation and cardiovascular disease: Application to clinical and public health practice: A statement for healthcare professionals from the Centers for Disease Control and Prevention and the American Heart Association. Circulation 2003;107: 499-511.

15. Pallasch TJ, Slots J. Oral microorganisms and cardiovascular disease. J Calif Dent Assoc 2000;28:204214.

16. Joshipura KJ, Hung HC, Rimm EB, Willett WC, Ascherio A. Periodontal disease, tooth loss, and incidence of ischemic stroke. Stroke 2003;34:47-52.

17. Czerniuk MR, Górska R, Filipiak KJ, Opolski G. Creactive protein in patients with coexistent periodontal disease and acute coronary syndromes. J Clin Periodontol 2006;33:415-420.

18. Cueto A, Mesa F, Bravo M, Ocaña-Riola R. Periodontitis as risk factor for acute myocardial infarction. A case control study of Spanish adults. J Periodontal Res 2005;40:36-42.

19. Blaizot A, Vergnes JN, Nuwwareh S, Amar J, Sixou M. Periodontal diseases and cardiovascular events: Metaanalysis of observational studies. Int Dent $J$ 2009;59: 197-209.

20. D'Aiuto F, Ready D, Tonetti MS. Periodontal disease and C-reactive protein-associated cardiovascular risk. J Periodontal Res 2004;39:236-241.

21. Montebugnoli L, Servidio D, Miaton RA, et al. Periodontal health improves systemic inflammatory and haemostatic status in subjects with coronary heart disease. J Clin Periodontol 2005;32:188-192.

22. Yoshii S, Tsuboi S, Morita I, et al. Temporal association of elevated C-reactive protein and periodontal disease in men. J Periodontol 2009;80:734-739.

23. Nakajima T, Honda T, Domon H, et al. Periodontitisassociated up-regulation of systemic inflammatory mediator level may increase the risk of coronary heart disease. J Periodontal Res 2010;45:116-122.

24. Fitzsimmons TR, Sanders AE, Bartold PM, Slade GD. Local and systemic biomarkers in gingival crevicular fluid increase odds of periodontitis. J Clin Periodontol 2010;37:30-36.

25. Shimada Y, Komatsu Y, Ikezawa-Suzuki I, Tai H, Sugita N, Yoshie H. The effect of periodontal treatment on serum leptin, interleukin-6, and C-reactive protein. $J$ Periodontol 2010;81:1118-1123.

26. Bretz WA, Weyant RJ, Corby PM, et al. Systemic inflammatory markers, periodontal diseases, and periodontal infections in an elderly population. $J$ Am Geriatr Soc 2005;53:1532-1537.

27. Ide M, McPartlin D, Coward PY, Crook M, Lumb P, Wilson RF. Effect treatment of chronic periodontitis on level of serum markers of acute-phase inflammatory and vascular responses. J Clin Periodontol 2003;30: 334-340.

28. Yamazaki K, Honda $\mathrm{T}$, Oda $\mathrm{T}$, et al. Effect of periodontal treatment on the $\mathrm{C}$-reactive protein and proinflammatory cytokine levels in Japanese periodontitis patients. J Periodontal Res 2005;40: 53-58.

29. Ainamo J, Bay I. Problems and proposals for recording gingivitis and plaque. Int Dent J 1975;25:229-235.
30. Pihlstrom BL, Ortiz-Campos C, McHugh RB. A randomized four-years study of periodontal therapy. $J$ Periodontol 1981;52:227-242.

31. Ramfjord SP. Indice for prevalence and indice of periodontal disease. J Periodontol 1959;30:51-59.

32. Gomes-Filho IS, Cruz SS, Rezende EJ, et al. Exposure measurement in the association between periodontal disease and prematurity/low birth weight. J Clin Periodontol 2007;34:957-963.

33. Brazilian Association for Obesity and Metabolic Syndrome Studies. Brazilian Guidelines on Obesity 2009/ 2010/ABESO - Brazilian Association for Obesity and Metabolic Syndrome Studies, 3rd ed. Sao Paulo: AC Farmacêutica; 2009.

34. World Health Organization. Obesity: preventing and managing the global epidemic. Report of a WHO consultation. World Health Organ Tech Rep Ser 2000;894:i-xii, 1-253.

35. Rutger Persson G, Ohlsson O, Pettersson T, Renvert S. Chronic periodontitis, a significant relationship with acute myocardial infarction. Eur Heart J 2003;24: 2108-2115.

36. Persson GR, Pettersson T, Ohlsson O, Renvert S. Highsensitivity serum $\mathrm{C}$-reactive protein levels in subjects with or without myocardial infarction or periodontitis. $J$ Clin Periodontol 2005;32:219-224.

37. Mattila K, Vesanen M, Valtonen V, et al. Effect of treating periodontitis on C-reactive protein levels: A pilot study. BMC Infect Dis 2002;2:30-32.

38. Craig RG, Yip JK, So MK, Boylan RJ, Socransky SS, Haffajee AD. Relationship of destructive periodontal disease to the acute-phase response. J Periodontol 2003;74:1007-1016.

39. Iwamoto Y, Nishimura F, Soga Y, et al. Antimicrobial periodontal treatment decreases serum C-reactive protein, tumor necrosis factor-alpha, but not adiponectin levels in patients with chronic periodontitis. $J$ Periodontol 2003;74:1231-1236.

40. Buhlin K, Hultin M, Norderyd O, et al. Risk factors for atherosclerosis in cases with severe periodontitis. $J$ Clin Periodontol 2009;36:541-549.

41. Balwant R, Jasdeep K, Simmi K, Rajnish J, S.C. Anand, Jaipaul S. Peripheral blood and C-reactive protein levels (CRP) in chronic periodontitis. African Biochem Res 2009;3:150-153.

42. Noack B, Genco RJ, Trevisan M, Grossi S, Zambon JJ, De Nardin E. Periodontal infections contribute to elevated systemic C-reactive protein level. J Periodontol 2001;72:1221-1227.

43. Fredriksson MI, Figueredo CM, Gustafsson A, Bergström KG, Asman BE. Effect of periodontitis and smoking on blood leukocytes and acute-phase proteins. J Periodontol 1999;70:1355-1360.

44. Slade GD, Offenbacher S, Beck JD, Heiss G, Pankow JS. Acute-phase inflammatory response to periodontal disease in the US population. J Dent Res 2000;79:49-57.

45. D'Aiuto F, Parkar M, Nibali L, Suvan J, Lessem J, Tonetti MS. Periodontal infections cause changes in traditional and novel cardiovascular risk factors: Results from a randomized controlled clinical trial. Am Heart J 2006;151:977-984.

46. Kinane DF, Riggio MP, Walker KF, MacKenzie D, Shearer B. Bacteraemia following periodontal procedures. J Clin Periodontol 2005;32:708-713. 
47. Woloshin S, Schwartz LM. Distribution of C-reactive protein values in the United States. N Engl J Med 2005;352:1611-1613.

48. Segundo TK, Ferreira EF, Costa JE. Periodontal disease in the Arturo's black community in Contagem, Minas Gerais, Brazil (in Portuguese).Cad Saude Publica 2004;20:596-603.

49. Macy EM, Hayes TE, Tracy RP. Variability in the measurement of C-reactive protein in healthy subjects: Implications for reference intervals and epidemiological applications. Clin Chem 1997;43:52-58.
50. Ebersole JL, Cappelli D. Acute-phase reactants in infections and inflammatory diseases. Periodontol 2000 2000;23:19-49.

Correspondence: Dr. Isaac Suzart Gomes-Filho, Avenida Getúlio Vargas, 379, Centro, Feira de Santana, Bahia 44.025-010, Brazil. Fax: 55-75-3623-0661; e-mail: isuzart@ gmail.com.

Submitted August 17, 2010; accepted for publication November 29, 2010. 